\title{
An Assessment of Livestock Production Potential in Pakistan: Implications for Livestock Sector Policy
}

\author{
MUZAFFAR IQBAL and MUNIR AHMAD
}

\section{INTRODUCTION}

About two third of the farming community in Pakistan consists of small farmers who are characterised by small land holdings (less than 5 hectares) and by several factors that influence their productive potential and income generating capacity [Pakistan (1998)]. Livestock farming is an integral part of rural smallholders and has a vast untapped potential for productivity increase and income generation. Livestock holdings by the small farmers constitute a significant portion of the farm incomes. Small farmers and landless livestock producers derive around $10-25$ percent of their incomes from this sub-sector. ${ }^{1}$

There have been and, largely, still are two primary purposes of raising livestock: (1) to meet the dietary needs of the rural and urban populace for milk and meat consumption; and (2) to fullfil the work performance requirements of the farm. Large ruminants receive more attention because of their capacity to perform both of the above functions. About 50 percent of the red meat supply in the country comes from large ruminants, yet beef production is not considered a separate specialised production activity. Rather it is treated as a by-product from animals kept for dairying and draught purposes. Most breeds of the large ruminants in Pakistan are famous for either milk production or draught power with hardly any beef breed. Therefore, the entire livestock production system revolves around milk production activity.

Livestock raising is closely integrated with crop production system partly because fodder production is a part of the crop rotation cycle and also because crop by-products and wastes are utilised by the livestock sector. In other words, all ruminant production systems depend heavily on crop residues, fodder grown on the farm and/or rangelands, wastelands and fallow lands.

Several studies have shown that livestock farmers, particularly the dairy farmers operating near urban centres, are economically efficient. This means that

Muzaffar Iqbal is Livestock Economist, Animal Sciences Division, Pakistan Agricultural Research Council and Munir Ahmad is Senior Research Economist, Pakistan Institute of Development Economics, Islamabad.

${ }^{1}$ Iqbal (1994) reported that small farmers and the landless in Barani areas generally receive 25 percent of their incomes from livestock sector whereas the proportion of income for these categories in irrigated areas has been estimated around 10 percent. 
commercially oriented livestock enterprises are efficient users of the resources [Iqbal et al. (1985)]. Furthermore, with the demand for livestock products growing rapidly, livestock farming has a comparative advantage for the production of livestock products. However, the profitability of raising livestock in the interior rural areas is comparatively low.

A rapidly growing economy, higher per capita incomes and rising population are the determinants of increase in the demand for livestock products [Byerlee and Iqbal (1987)] which exerts a continuous pressure on the country's livestock resource base. In Pakistan, the increase in animal products has mainly been the result of an increase in animal numbers, not productivity per animal. However, improved animal efficiency will be an imperative necessity for future increase in food production [Dahlin (1998)].

One popular hypothesis often discussed is that our national livestock herd consists of a substantial number of unproductive and low productive animals that claim their share in feeding and management leaving less for the more productive stock. This, in turn, decreases national averages of milk and meat production. Secondly, the composition of the national herd is also not economical and appropriate in several ways. This means that our national herd with its present level of per animal productivity is unable to meet the rising demand for livestock products.

The purpose of this study is to develop a model herd structure using the milk production efficiency criteria and compare our national herd with the model to identify gaps in livestock production, research, and development. The remaining paper is organised in five sections. Section 2 briefly explains the structure of the model used for identifying the productivity or yield gap. Data sources are described in Section 3 followed by Section 4 in which major findings of the paper are presented. Section 5 presents the constraints faced by the livestock sector and policy alternatives. The last section concludes the paper.

\section{THE MODEL OF YIELD GAP}

Productivity or yield gap is defined as the differential between the actual yield being obtained from an animal of a breed and the maximum possible potential yield of the breed that can be obtained by adopting different production strategies and management practices. The concept of yield gap is illustrated in Figure 1.

Consider the milk production technology as characterised by a production function $Y=f(X)$, where $Y$ is maximum potential milk yield, $X$ is a vector of nonstochastic physical inputs such as labour, green and dry fodder, concentrates, vaccines and veterinary medicines, breeding and reproduction practices etc. Every 
animal of the breed may not be able to produce the maximum output since the

\section{Fig. 1. Concept of the Yield Gap.}

amount of output obtained from a given level of inputs depends not only on the technological level " $f($.$) " or the breed but also on the productive efficiency (genetic$ quality) that varies from one animal to another within the same breed. An animal is productively efficient if it is producing at a point on the production frontier " $f(X)$ " such as $A, B$, or $C$. Those giving yields below the production frontier like $D$ or $E$ are inefficient because with their breed's maximum potential they could yield higher output with the same amount of inputs. Obviously they cannot produce at point $H$ because it is a point beyond their productive capacity. The distance between the $Y D$ and $Y B$ measures the yield gap. An animal producing at point $D$ is relatively more efficient than an animal producing at point $E$, presumably because animals at point $D$ receive better management. The productive differential of the animals is calculated as follows:

$$
\text { Yield Gap }=(Y B-Y D)
$$

\section{DATA SOURCES}

The analysis presented in this paper is based on the 1996 livestock census data [Pakistan (1997)]. The census data of the national herd structure pertaining to major breeds of buffalo and cattle were used for estimating yield gaps separately for each breed. The total number of animals in each breed, the number of in-milk females, dry animals, those not yet calved and the youngs under the age of one year were considered.

Reliable data on productivity parameters for different dairy breeds of cattle and buffalo under different management regimes are generally not available. Bhutto et al. (1993) reported milk production levels of major dairy breeds of the country. These are considered as the national averages of milk production by indigenous breeds maintained by the livestock producers. The data on national milk production 
averages and milk production potential of different dairy breeds of buffalo and cattle are given in Table 1. These averages and breed potentials are achievable at the research stations and at the progressive livestock farms.

Table 1

National Averages of Milk Production at Farmers' Level and Production Potentials of Different Breeds (Liters Per Lactation)

\begin{tabular}{lccc}
\hline Breeds & National Average & Research Station & Breed Potential \\
\hline Nili-Ravi & 2300 & 3150 & 5000 \\
Kundi & 2000 & 3000 & 3500 \\
Other & 1769 & 2500 & 3000 \\
Sahiwal & 2200 & 3600 & 6500 \\
Red Sindhi & 1800 & 2700 & 4000 \\
Thari & 1200 & 1800 & 2160 \\
Bhagnari & 800 & 1160 & 1392 \\
Rojhan & 900 & 1305 & 1566 \\
Dhani & 800 & 1160 & 1392 \\
Kankraj & 1200 & 1740 & 2088 \\
Lohani & 700 & 1015 & 1218 \\
Cross Bred & 2600 & 3600 & 4320 \\
Others* & 700 & 1015 & 1218 \\
\hline
\end{tabular}

*Includes non-descript buffaloes and cattle.

The data for milk production of various breeds maintained at the research station are obtained from several Annual Reports of Livestock Production and Research Institute, Bahadur Nagar, Okara [DLPRI (1983-84 and various issues)]. Performance record of the dairy animals reported at the research stations belongs to elite animals maintained mostly for breed improvement programmes. Such production performance is generally shown by 10 percent of the elite animals of a breed.

Several researchers have reported data on maximum milk production potential of the breeds. Shah (1991) reported that Nili-Ravi is the best dairy breed in the world with a maximum milk production potential of 5000 liters per lactation of 305 days followed by Kundi breed with a maximum potential of 3500 liters. Similarly, Hasnain and Shah (1985) reported that maximum breed potential observed in the elite animals of Sahiwal is up to the extent of 6500 liters of milk per lactation of 305 days. Red Sindhi cattle have a maximum breed potential of 4000 liters [Wahid (1975 and 1975a)]. The maximum breed potential for all other breeds (from Thari to Other breeds) has been estimated as 20 percent higher than the yield observed at the research station. The national averages are reported in Table 1.

\section{RESULTS AND DISCUSSION}

\section{Yield Gaps}


The yield gap in milk production in respect of various breeds listed in Table1 was estimated following the yield gap model discussed in Section 2. These gaps were empirically estimated by using livestock census data in combination with productivity coefficients given in Table1. These estimates are presented in Table 2.

Table 2

Specie-wise and Breed-wise Milk Yield Gap

\begin{tabular}{|c|c|c|c|c|c|c|c|}
\hline \multirow[b]{2}{*}{$\begin{array}{l}\text { Breed } \\
\text { (1) }\end{array}$} & \multicolumn{2}{|c|}{ Thousand Numbers } & \multicolumn{5}{|c|}{ Thousand Tons } \\
\hline & $\begin{array}{l}\text { Total } \\
\text { No. } \\
\text { (2) }\end{array}$ & $\begin{array}{c}\text { In-Milk } \\
\text { (3) }\end{array}$ & $\begin{array}{c}\text { CurntProd } \\
\text { (4) }\end{array}$ & $\begin{array}{c}\text { Res.Stn } \\
(5)\end{array}$ & $\begin{array}{c}\text { Yld- } \\
\text { Gap1 } \\
\text { (6) }\end{array}$ & $\begin{array}{l}\text { Breed } \\
\text { Max } \\
\text { (7) }\end{array}$ & $\begin{array}{c}\text { Yld- } \\
\text { Gap2 } \\
\text { (8) }\end{array}$ \\
\hline Nili-Ravi & 6777.66 & 2582.8 & 5940.5 & 8136. & 2195 & 12914. & 6973. \\
\hline Kundi & 4282.06 & 1776.4 & 3552.8 & 5329. & 1776 & 6217. & 2664. \\
\hline Other Buff & 9213.15 & 3450.2 & 6103.4 & 8625. & 2522 & 10350. & 4247. \\
\hline Sahiwal & 1392.32 & 504.5 & $1110 . C$ & 1816. & 706 & 3279. & 2169. \\
\hline Red Sindhi & 1939.73 & 682.4 & 1228.3 & 1842. & 614 & 2729. & 1501. \\
\hline Thari & 1412.88 & 405.6 & 486.7 & 730. & 243 & 876. & 389. \\
\hline Bhagnari & 496.85 & 139.8 & 111.8 & 162. & $5 \mathrm{C}$ & 194. & 82. \\
\hline Rojhan & 212.82 & 95.3 & 85.8 & 124. & 38 & 149. & 63. \\
\hline Dhani & 1389.75 & 376.5 & 301.2 & 436. & 135 & 524. & 222. \\
\hline Kankraj & 54.04 & 20.5 & 24.7 & 35. & 11 & 42. & 18. \\
\hline Lohani & 232.49 & 62.7 & 43.9 & 63. & 19 & 76. & 32. \\
\hline Cross Bred & 1541.33 & 574.1 & 1492.8 & 2067. & 574 & 2480. & 987. \\
\hline Other Cow & 11752.21 & 3464.2 & 2424.9 & 3516. & 1091 & 4219. & 1794. \\
\hline \multicolumn{3}{|c|}{ Milk Produced by Buff and Cows } & 22907.4 & 32886. & 9978 & 44055. & 21148. \\
\hline
\end{tabular}

Columns 2 to 4 of Table 2 present breed-wise number of total livestock, number of in-milk animals and the current milk production, respectively. The yield gap is estimated in two scenarios. Firstly, if the production potential achievable at research station for each breed is extrapolated for all in-milk animals of the breed, the milk production thus achieved is given in Column 5. The difference between current level of milk production (Column 4) and achievable at research station (Column 5) is given in Column 6 as the Yield Gap-1. Secondly, the maximum milk production potential is still much higher, which is depicted in the elite herds that are usually maintained at research stations or at private livestock farms. ${ }^{2}$ If the present milk production (Column 4) is compared with the maximum genetic potential (labelled as Breed Max in Column 7) the difference is estimated as the Yield Gap-2 (Column 8).

From a close comparison of the current milk production performance of the national herd (Column 4) with the probable production levels (Column 5 and 7), one 
can conclude that per animal productivity in Pakistan is far below than its genetic potential. The last row of Table 2 summarises the aggregates of milk production by buffaloes and cows. It shows that present milk production is 22.9 million tons. However, with exploitation of the genetic potential of dairy animals, the quantum of milk production can be increased from 50 to 100 percent (Columns 5 and 7).

${ }^{2}$ Some private farms raise elite animals of the pure breeds as a hobby or for participating in national cattle shows where such animals are presented for milk production championships.

\section{Livestock Herd Composition}

The herd composition refers to various types of animals maintained in a herd. The types of animals, in turn, refer to distinction of the animals according to their sex, age, and type of work they perform. A herd contains male and female adult animals, animals from 1 to 3 years of age, and calves below one year of age. For example, male animals can be divided into several categories namely; males for work, for breeding, calves from 1 to 3 years of age, calves below one year of age. Similarly, female animals of the herd can be divided into the categories like adult in-milk females, dry females, not yet calved, below one to 3 years, and calves below one year. The composition of the national livestock herd is summarised in Tables 3 and 4 . Table 3 and Table 4 respectively, summarise the herd composition of all the breeds of buffalo and cattle populations found in Pakistan. Column 1 in both the tables lists various categories of male and female animals as mentioned above.

Herd composition analysis takes into account the two scenarios earlier developed for estimating the yield gaps. Column 2 shows census data (actual number) of animals in various categories. In Tables 3 and 4, Columns 2 to 5 refer to Scenario I in which milk production potential of animals exhibited at a research station is considered as the key indicator for estimating required number of animals in each category. The required number of animals in each category has been estimated in both the tables (Column 3). When these estimates are compared with the actual number (Column 2), a huge difference is noted in Column 4 . The difference is to the tune of 5.9 million buffaloes and 6.4 million cows. This implies that if the research station production coefficients are extrapolated for all the in-milk animals throughout the country, then we will require 14.3 million buffaloes as against the present total of 20.2 million ( 29 percent less) and 13.9 million cows as against the present total of 20.4 million (32 percent less). Throughout the estimation process, due consideration was given for various requirements of the animals. For example, it was considered that both the buffaloes and cows maintained for work purposes will not change. 
Following Scenario II developed in our discussion of Yield Gap-2, where maximum breed potential are extrapolated for the entire in-milk stock, the estimates are presented in Columns 6 to 9 of Tables 3 and 4. The required number of buffaloes in the national herd would be 10.9 million (Column 7) as against present total of 20.27 million (45 percent less) and 11.8 million cows as against present total of 20.4 million (45 percent less). 
Table 3

National Versus Elite Herd Composition of Buffaloes in Pakistan

\begin{tabular}{|c|c|c|c|c|c|c|c|c|}
\hline \multirow[b]{2}{*}{$\begin{array}{c}\text { Type } \\
\text { (1) }\end{array}$} & \multicolumn{4}{|c|}{ Scenario I } & \multicolumn{4}{|c|}{ Scenario II } \\
\hline & $\begin{array}{l}\text { Actual } \\
\text { (2) }\end{array}$ & $\begin{array}{l}\text { Required } \\
\text { (3) }\end{array}$ & $\begin{array}{c}\text { Difference } \\
\text { (4) }\end{array}$ & $\begin{array}{c}\text { \% less } \\
\text { (5) }\end{array}$ & $\begin{array}{c}\text { Actual } \\
(6)\end{array}$ & $\begin{array}{l}\text { Required } \\
\text { (7) }\end{array}$ & $\begin{array}{c}\text { Differen } \\
(8)\end{array}$ & $\begin{array}{c}\text { \% less } \\
(9)\end{array}$ \\
\hline Total No. & 20272.88 & 14322.70 & -5950.17 & 29 & 20272.88 & 10997.31 & -9275.57 & 46 \\
\hline Male Breed & 197.85 & 139.26 & -58.59 & 30 & 197.85 & 108.45 & -89.40 & 45 \\
\hline Male Work & 163.01 & 163.01 & 0.00 & 0 & 163.01 & 163.01 & 0.00 & 0 \\
\hline Male Below 1 & 2799.93 & 1978.20 & -821.73 & 29 & 2799.93 & 1520.44 & -1279.49 & 46 \\
\hline Male -1 to 3 & 486.30 & 343.33 & -142.97 & 29 & 486.30 & 265.25 & -221.05 & 45 \\
\hline Female In-milk & 7809.52 & 5511.57 & -2297.95 & 29 & 7809.52 & 4237.70 & -3571.81 & 46 \\
\hline Dry & 2433.29 & 1720.18 & -713.11 & 29 & 2433.29 & 1321.50 & -1111.79 & 46 \\
\hline Not Calved & 1968.30 & 1392.06 & -576.24 & 29 & 1968.30 & 1063.38 & -904.92 & 46 \\
\hline Below 1 & 3231.82 & 2284.51 & -947.30 & 29 & 3231.82 & 1752.73 & -1479.09 & 46 \\
\hline 1 to 3 & 1182.85 & 839.55 & -343.30 & 29 & 1182.85 & 637.04 & -545.82 & 46 \\
\hline
\end{tabular}

Table 4

National Versus Elite Herd Composition of Cows in Pakistan

\begin{tabular}{|c|c|c|c|c|c|c|c|c|}
\hline \multirow[b]{2}{*}{$\begin{array}{c}\text { Type } \\
\text { (1) }\end{array}$} & \multicolumn{4}{|c|}{ Scenario I } & \multicolumn{4}{|c|}{ Scenario II } \\
\hline & $\begin{array}{c}\text { Actual } \\
\text { (2) }\end{array}$ & $\begin{array}{l}\text { Required } \\
\text { (3) }\end{array}$ & $\begin{array}{c}\text { Difference } \\
\text { (4) }\end{array}$ & $\begin{array}{c}\text { \% less } \\
(5)\end{array}$ & $\begin{array}{c}\text { Actual } \\
(6)\end{array}$ & $\begin{array}{c}\text { Required } \\
(7)\end{array}$ & $\begin{array}{c}\text { Difference } \\
(8)\end{array}$ & $\begin{array}{c}\text { \% less } \\
(9)\end{array}$ \\
\hline Total No. & 20424.42 & 13949.58 & -6474.85 & 32 & 20424.42 & 11182.09 & -9242.33 & 45 \\
\hline Male Breed & 280.83 & 191.72 & -89.10 & 32 & 280.83 & 153.72 & -127.11 & 45 \\
\hline Male Work & 3389.05 & 3389.05 & 0.00 & 0 & 3389.05 & 3389.05 & 0.00 & 0 \\
\hline Male Below 1 & 2789.04 & 1903.93 & -885.10 & 32 & 2789.04 & 1521.79 & -1267.25 & 45 \\
\hline Male 1 to 3 & 779.15 & 533.19 & -245.96 & 32 & 779.15 & 430.13 & -349.02 & 45 \\
\hline Female In-milk & 6326.15 & 4316.92 & -2009.23 & 32 & 6326.15 & 3439.21 & -2886.93 & 46 \\
\hline Dry & 2381.10 & 1629.00 & -752.10 & 32 & 2381.10 & 1317.24 & -1063.86 & 45 \\
\hline Not Calved & 1313.70 & 896.46 & -417.24 & 32 & 1313.70 & 717.71 & -595.99 & 45 \\
\hline Below 1 & 2360.97 & 1612.36 & -748.61 & 32 & 2360.97 & 1287.78 & -1073.19 & 45 \\
\hline 1 to 3 & 804.51 & 550.89 & -253.62 & 32 & 804.51 & 443.71 & -360.80 & 45 \\
\hline
\end{tabular}


Livestock production experts assert that our national livestock herd is undernourished to the extent of 30-40 percent, which is presented as a reason for low per animal productivity. The above analysis implies that we should consider culling our less or non-productive stock. This would release huge amounts of feed and management resources for the more productive stock leading to substantial yield increases.

There could be several explanations for the yield gap. Livestock professionals assert that better nutrition, selection of quality breeds, culling of unproductive animals and adoption of proper management regimes are needed to exploit the available genetic potential.

\section{MAJOR CONSTRAINTS AND DEVELOPMENT POLICY ALTERNATIVES}

\section{Major Constraints}

Iqbal (1994) summarised the major constraints to improve the livestock productivity in Pakistan and argued that they can be grouped into three categories namely: Nutritional Constraints (Feed Gap); Inadequate Support Services; and Market and Policy Constraints.

\section{Nutritional Constraints}

Total livestock feed resources available in the country have been estimated at 47.3 million tons of total digestible nutrients (TDN) and 4.32 million tons of digestible protein (DP). Of the total feed supply, the crop sector contributes about 60 percent of TDN and rangelands provide 11 percent of total TDN. Other grasing which includes river banks, wastelands, road sides, fallow and forested grass lands makes an important contribution to feed resources, with 27 percent of total dry matter (DM).

Livestock feed requirements have been estimated at 60.16 million tons of TDN and 5.46 million tons of DP. These requirements have been calculated at 70 to 80 percent of the potential requirements to exploit full genetic resources. The feed gap is huge and warrants immediate attention.

To narrow the feed gap, various research institutions have evolved nutritional technologies that have proved economical and biologically viable. Unfortunately the delivery system (livestock extension system) is not efficient to disseminate the technologies to bring a breakthrough in the national situation of feed scarcity. It is therefore, a need of over time that these technologies are tested on the farms under the farming system perspective/outreach research programmes. 


\section{Support Services}

The livestock departments in the four provinces give overwhelming importance to adequate provision of animal health services to the livestock owners. These services include diagnosis and treatment of diseases, vaccination programmes and production of biological vaccines.

The most important diseases of livestock are foot and mouth disease (FMD), hemorrhagic septicemia, black quarter, rinderpest in cattle and buffaloes, and sheep pox, anthrax and enterotoxaemia in sheep and goats. These diseases cause heavy economic losses particularly in buffalo and cattle. In poultry, major diseases are New-castle disease, mycoplasmosis, salmonellosis, Merek's disease, leucosis, Gumboro disease, and fowl pox. These diseases in poultry cause mortality to the extent of 7 percent in broiler and 15 percent in layer farms.

The animals actually vaccinated every year may not be more than 10 percent of the livestock population. Vaccines are produced in the public sector while all other drugs are produced by the private sector, which are purchased by the public sector to be distributed to all the veterinary hospitals and dispensaries. Financial assistance to livestock sector is very low as compared to crop sector. The budgetary allocations cover only a very small part of the costs of necessary drugs.

\section{Market and Policy Constraints}

The existing milk marketing system for commercial dairies is not capable of adjusting with the seasonal fluctuations in the supply and demand for milk. When urban demand for milk is higher (in summer), the supply is relatively inelastic (basically due to limited capacity of the milk vendors). Conversely, when supply increases in winter, the demand is relatively inelastic. This is due to less consumer demand for processed milk. This means that the existing marketing system has failed to operate at its own in a competitive market economy. The most limiting factor in the expanded milk marketing system is the lack of infrastructure in the rural areas.

The entire UHT industry is using only less than 2 percent of the total milk produced in the country. At the same time export of processed dairy products is discouraged and the industry does not find its way out especially when the local demand for the processed products is not very high.

\section{Development Policy Imperatives}

For rapid and continuous development of the livestock sector, the economically viable tested technologies developed at research stations are to be transferred to the farmer's field. Technologies developed in the fields of nutrition, 
vaccination, and artificial insemination are readily available for the extension system.

Pakistan is fortunate to be the home tract of some of the finest breeds of livestock as compared with other regional countries. There are two buffalo breeds namely, Kundi and Nili-Ravi and eight discrete breeds of cattle. There are about 28 breeds of sheep and more than 20 breeds of goats recognised in Pakistan [Hasnain (1985)]. Breed improvement work in Pakistan has mainly revolved around artificial insemination (AI) programmes [Usmani and Shah (1986) and Khan (1994)]. Despite the fact that the government has huge infrastructure for the AI service in the country, the actual coverage of AI service to adult buffalo and cattle females could not be increased more than 3 percent. Efforts should be made to increase the AI coverage both in buffalo and cattle for up-gradation of our genetic stock.

Milk production in Pakistan is in the hands of millions of small landholders or landless people. Farmers, whose principal occupation is agriculture, keep a few dairy animals for milk production either for home consumption or as a supplementary source of income. A major portion (about 70 to 80 percent) of this milk is converted into milk products (e.g. ghee) due to transport difficulties in shipping fluid milk from villages to distant urban markets.

There are thousands of traders collecting small quantities of milk from producers in the area. These traders belong usually to the poorer segment of the society. The existing marketing has been functioning without much attention by the policy-makers and planners. If it is required that the dairy industry should survive, the milk marketing system will have to be improved. The milk collection units be established more densely which collect, chill and market the available milk. Currently, all of milk plants are operating at under capacity resulting in higher per unit cost (fixed costs spread over smaller output raising the retail price of milk). The possible options to come out of this dilemma are: (1) the government should stop further loaning for the establishment of milk plants, (2) the milk processing industry as well as government has to review the pricing policy in favour of the ultimate consumers. This will increase demand for the products, (3) establishment of mini dairies around big cities, (4) organisation of milk cooperative societies/union of producers for efficient milk production, collection and marketing system.

\section{CONCLUSIONS}

This paper has described a simple quantitative framework for livestock development planning. Specifically, it provides a useful tool for use in typical planning situation-the estimation of livestock resources required for meeting specified production targets. By doing so, we can estimate the required number of 
total as well as in-milk livestock that would be sufficient to achieve the given level of production target. An analysis of the yield gap in milk production has been made. The yield gap is estimated in two scenarios. Firstly, if the production potential achievable at research stations for each breed is extrapolated for all in-milk animals of the breed, the milk production thus achieved is the Yield Gap-1. The gap comes equivalent to about 50 percent of the present milk production. The second scenario is developed with a hypothesis that the maximum milk production potential is still much higher, which is depicted in the elite herds that are usually maintained at research stations or at private livestock farms. Yield Gap-2 comes equivalent to about 100 percent of the present milk production. The composition of the national livestock herd is also analysed by considering the two scenarios of the yield gaps. Under Scenario I, the required number of animals in each category were less to the tune of 5.9 million buffaloes ( 29 percent less) and 6.4 million cows ( 32 percent less).

There are large gaps in the data set and that where data exist, they are mostly estimates. The paucity of data on key parameters like breed-wise production coefficients, production potential estimates, particularly under varying feeding and management regimes were noted. It is to be noted that relatively marginal variations in the values of key parameters can produce significant changes in results. Such data problems are widely recognised.

\section{REFERENCES}

Bhutto, M. A., M. A. Khan, and G. Ahmad (1993) Livestock Breeds of Pakistan. Islamabad: Ministry of Food, Agriculture, and Cooperatives (Livestock Division), Government of Pakistan.

Byerlee, D., and M. Iqbal (1987) Recent Trends and Variability in Prices of Selected Crops and Livestock Products in Pakistan. Pakistan Journal of Agricultural Social Sciences 1: 2.

Dahlin, Anders (1998) Genetic Studies on Sahiwal Cattle in Pakistan. Doctoral Thesis, ACTA Universitatis Agricultureae Sueciae. Agraria 99. Swedish University of Agricultural Sciences. Uppsala.

DLPRI (Directorate of Livestock Production Research Institute) (1983-84 and Various Issues) 5th Annual Report 1983-84. Okara: Bahadur Nagar Farm.

Hasnain, H. U. (1985) Sheep and Goats in Pakistan. Rome: FAO Animal Production and Health Paper 56, FAO.

Hasnain, H. U., and S. K. Shah (1985) Sahiwal Cattle of Pakistan. Islamabad: Pakistan Agricultural Research Council.

Iqbal, M., Zakir Hussain Rana, and Agha Sajjad Haider (1985) Resource Use Efficiency of Dairy Enterprise in the Punjab-Pakistan. The Journal of 
Development Studies 7.

Iqbal, Musaffar (1994) Major Constraints to Livestock Production in Pakistan. Paper presented at the First SAARC Training Programme on Socio-economic Techniques to Identify Constraints to Agricultural Production in Pakistan, Held at NARC, Islamabad, May 29-31.

Khan, U. N. (1994) Genetic Improvement of Native Cattle Through Crossbreeding and Introduction of Exotic Dairy Cattle in Pakistan. Islamabad: Pakistan Science Foundation.

Pakistan, Government of (1997) Pakistan Census of Livestock 1996: Final Report. Islamabad: Agriculture Census Organisation.

Pakistan, Government of (1998) Economic Survey of Pakistan. Islamabad: Ministry of Finance.

Shah, S. K. (1991) Buffaloes of Pakistan. Islamabad: Pakistan Agricultural Research Council.

Usmani, R. H., and S. K. Shah (1986) Establishment of Nucleus Jersey Herd for the Improvement of Non-Descript Cattle of Barani Areas in Pakistan. Islamabad: Pakistan Agricultural Research Council.

Wahid, A. (1975) Livestock Resource of Pakistan. Karachi: University of Karachi. (Monograph-6: Shahiwal Cattle.)

Wahid, A. (1975a) Livestock Resource of Pakistan. Karachi: University of Karachi. (Monograph-1: Red Sindhi Cattle.) 


\section{Comments}

The role of livestock in the development of agriculture sector cannot be underscored. The bulk of livestock production in the country is in the hands of millions of small producers scattered all over the country. They adopt this business as a source of regular income. Pakistan is fortunate enough to have some of the best breeds of livestock and they are high in number per hundred persons as compared to foreign countries but have poor yields due to lack of good management and feeding. Therefore, any study that attempts to look at the production potential of livestock under given constraints, is addressing an important need of Pakistan.

The paper under discussion attempts to do so through an interesting use of the primary data from annual reports of the Bahadarnagar Livestock Production and Research Institute and secondary data based on the Livestock Census Report 1997. Its stated intent is to develop a model herd structure using the efficiency criteria and to compare the national herd with the model to identify the gaps in livestock production, research and development.

The study uses tabular analysis based on theoretical yield gaps estimated by using livestock census data in combination with productivity coefficients derived from the research station data and reports 50-100 percent yield gap across research station farm and national herd, respectively. The paper also describes the major constraints to increase the livestock productivity in Pakistan.

The general thrust of the paper and its eventual objective is useful i.e. it estimates the gap in production potential and provides suggestions to eliminate the constraints towards higher livestock productivity. However, the paper, in its present form, does not go for meeting its objectives. I list below a number of weaknesses in the analysis that affect the credibility of results.

To start with, the study has not taken into consideration the productivity differences, which exist on the other livestock farms across the country and spatial differences of low productivity of livestock in different areas of Pakistan. In the absence of such data the estimates may not be representing the true picture. Secondly, the study has serious methodological flaws, as neither does it indicate how the estimates of productivity coefficients were arrived at nor does it mention how it worked out the required number of animals in the national herd. The paper also does not address the fundamental questions such as: What are the characteristics of the livestock owners? Why do they prefer to keep low productivity on the farms? How they can be mobilised to cull the unproductive animals and to keep the productive ones? One gets the uneasy feeling that by ignoring these questions the authors are 
assuming that the farmers and those connected with the livestock enterprise in Pakistan are somehow irrational. This is definitely not the case. In order to make any policy recommendations this paper needs to address the reasons for low livestock productivity across farm categories. These reasons can easily be highlighted by conducting a comparative analysis of these factors across small, medium, large and non-farm categories in the sample and would help to provide credibility to the results and effective policy prescription to the study.

Ministry of Food, Agriculture and Livestock,

Waqar A. Jehangir Islamabad. 